\title{
HISTORY IN MOTION
}

\section{USING BROADCAST MEDIA CONTENT IN THE TEACHING AND LEARNING OF HISTORY - SOME EDUCATIONAL REFLECTIONS}

\author{
Alexander Cutajar \\ University of Malta \\ alex.cutajar@um.edu.mt
}

\begin{abstract}
The subject of this paper is the use of broadcast media content - newsreels, news reportage and non-fiction documentaries - in the history classroom. Used educationally as sources of evidence, such moving images offer students a valuable learning experience. Drawing on findings from a study involving students analysing media content in a Maltese secondary history classroom, I report how students preferred the documentary-type of broadcast content. Students demonstrated an awareness of disciplinary knowledge when analysing moving images and highlighted certain limitations. Teacher questions were key to driving the analysis forward. I place these findings within the general goal of helping students become visually literate. It is hoped that the reflections offered will help educators maximise the use of broadcast media content to promote effective learning in history and increase awareness among researchers and practitioners of television history and culture about educationally-relevant content.
\end{abstract}

Keywords: broadcast media, moving images, secondary history, history classroom, Malta

\section{Introduction}

The merits of broadcast media content to teaching and learning history have long been recognised. In 1976, Haworth had argued:

Films, whether dramatic, documentary or newsreel, can encourage identification and create atmosphere. To see and hear Martin Luther King, to watch the spectacle of a Nuremberg rally, to follow the evolution of the written word, or to observe the ordered existence of a medieval monastery: all provide in different ways a necessary historical experience. ${ }^{1}$

At the heart of Haworth's argument is a history that is in motion and which provides an experience made unique by the visual and auditory elements of moving images. However, with a history education that foregrounds disciplinary thinking through the use of second-order concepts (e.g., evidence, cause and consequence, change and continuity), ${ }^{2}$ on its own this experience is not enough; it needs to be supported by a pedagogical approach that focuses on the critical analysis of media content with the aim of nurturing visual literacy in students. Such media content includes footage of key historical events captured live on camera and shown on newsreels, broadcast on television, or incorporated in historical documentary which, in history education, are seen as contemporary history sources. ${ }^{3}$ 
With a wealth of online digital material ${ }^{4}$, there is never a shortage of broadcast media content and with online access through portals such as YouTube, EUscreen and Historiana, teachers are provided with ample opportunities to explore the potential of such broadcast media as an educational tool in the teaching and learning of history.

Looking into ways how broadcast media may contribute towards understanding history as a discipline, this paper explores the pedagogical use of broadcast media in the history classroom by discussing findings from a study $^{5}$ in a Maltese state secondary school with 15/16-year-old students in their final year of secondary school (Year 11). It highlights students' preferred moving images and what procedural knowledge was deployed when students analysed broadcast media. The paper also shows which questions may hold potential to drive the analysis of broadcast content forward. This is followed by a discussion about the implications for using broadcast media in a classroom context. Findings are then placed within the broad framework of developing visual literacy. I argue that the key to having an informed public, appreciative of television history, is an education that places the interrogation of sources on centre stage. It is emphasised that we have to look at broadcast media not merely as sources of historical information but also as a way of engaging with the past in order to understand history's interpretative and contested nature. The insights offered are aimed, first, at helping educators maximise the use of broadcast content in the classroom to promote effective learning in history and, secondly, at increasing awareness among researchers and practitioners of television history and culture about educationally-relevant content.

\section{The Educational Value of Audiovisual Heritage}

Momentous historic events have been given extensive media coverage ${ }^{6}$ While for people in past times such moving images were an important source of information about contemporary world affairs, ${ }^{7}$ for us nowadays they constitute a record of historical events. Significantly, they embody an audiovisual heritage of immense educational value. However, this heritage remains idle material unless viewed, analysed and appreciated. With a multitude of television programmes making ample use of audiovisual heritage, historical television has been increasingly seen as a way of providing the public with access to history. ${ }^{8}$ This access has been made even more comfortable with the digitisation and online availability of television programmes, thus affording, when analysed, multiple European perspectives to television history. Indeed, the pivotal role of historical television in the public history domain is undisputed.

Broadcast media images are important in their own right and are appealing to students for multiple reasons. Taken together, these images open a window onto defining moments in history, portraying both high-profile politicians and the man-in-the-street along their voices and first-hand experiences. Such images bring the visual and the aural elements together to offer a glimpse into the protagonists' mixed emotions: excitements and disappointments; elations and concerns; actions and reactions.

Broadcast media content also has great educational potential: it captures the atmosphere of an event in real time; renders the sensation of movement better than still images do; conveys a sense of what it was like to experience hard times or help realise how people's daily life was like in different time periods; and offers a sense of place. Having such broad appeals to the senses, broadcast content delivers on students' interests in more ways than one. Furthermore, with a syllabus that emphasises students' exposure to as wide a variety of sources as possible in their history education and a critical engagement with such sources, ${ }^{9}$ broadcast media constitute a useful source for studying the past.

In an educational context influenced by technology, ${ }^{10}$ using such ready-made online material as sources of evidence in the history classroom offers students a valuable learning experience. In an effort to address criticism that the public 
passively consumes televised history because of its exclusion from historians' research and interpretation, ${ }^{11}$ the need to inculcate in students' skills of analytic engagement with broadcast media is paramount. Adopting a critical approach to broadcast media means that as well as analysing the moving images for the historical knowledge they offer, students must also focus on making sense of the language used, extracting the evidence in relation to the lesson's enquiry, and understanding the contemporary and present-day historical significance of media content, among others. ${ }^{12}$ In this way, the experience offered by watching and analysing broadcast media content becomes both informative and enriching.

In exploring this further, I follow a strong tradition of teaching history using moving images, ${ }^{13}$ ranging from television programmes to fiction films and historical documentaries, to attend to history's disciplinary aspects in the classroom. In seeking to address a major concern raised by Donnelly (2013) that teachers are not as comfortable interrogating moving images as they are with printed historical sources, ${ }^{14}$ I subscribe to the suggestion advanced by de Leeuw of having digital European history and culture embedded in curricula. ${ }^{15}$ Against this background, this study set out to explore how broadcast media can be used for educational gains.

\section{Methodology}

The aim of the research was to explore the use of broadcast media content in history lessons in terms of motivation, engagement and historical understanding. The study was conducted among three Year 11 cohorts across three scholastic years, following the history option programme. History is a compulsory subject across the secondary school years (Years $7-11$ ) but students may opt to study it in more depth as an option subject from Years 9 through 11. Therefore the population of history option classes is dependent upon the number of students choosing history as an option subject, which varies from one year to another. The total number of participants was 22 students (cohort $1=8$; cohort $2=4$; cohort $3=10$ ) and my role was that of teacher-researcher. Although the size of participating cohorts reflects other history option classes in Malta, this study did not purport to make any generalisations. Adhering to formal ethical procedures, ${ }^{16}$ data were derived from semi-structured group interviews, whole-class teacher-students dialogues, and students' writings. The interviews were carried out at the beginning and end of the scholastic year. Lessons were audio-recorded, transcribed and analysed using the software QSR Nvivo11. Regarding the medium of instruction, lessons were carried out mainly in Maltese. Being a bilingual nation, code-switching between Maltese and English languages is a common phenomenon in Malta. Changing to the English language by both students and me to express words, phrases, questions or whole sentences took place, consciously or unconsciously, all the time.

Transcribed data were divided into segments of meaningful content. ${ }^{17}$ Each segment represented a unit of analysis containing verbal utterances about an idea or concept. Based on emerging classroom data and on the relevant literature, these segments were coded according to the three areas under review: motivation, engagement and understanding. The coding scheme for the area of historical understanding, which is the focus of this paper, covered such categories as concepts, particulars, people and historical context for substantive knowledge and evidence, causes, consequences, change and continuity, significance, interpretation and empathy for procedural knowledge. In this way, units of analysis could be analysed both quantitatively and qualitatively.

The history programme for this year group comprised twentieth and twenty-first Maltese and international history, covering topics as 'Malta during the Second World War', 'the Cold War', 'European integration' and 'Terrorism'. To promote an understanding of history from a disciplinary perspective, students are expected to analyse and place evidence in context, detect bias, compare sources and make inferences and conclusions from evidence. For a sharper focus, I limited the moving images to broadcast media content featuring in newsreels (e.g., British Pathé), news reportage and non-fictional documentaries (Table 1). Those chosen were 
commensurate with the syllabus topics and used in conjunction with other types of historical sources (e.g., historical photographs, newspaper articles).

Table 1. Examples of broadcast media content.

\begin{tabular}{|c|c|c|c|}
\hline Categories & Screenshot & Source & Description \\
\hline Newsreel &  & Berlin Air Lift (1949) & $\begin{array}{l}\text { British Pathé news- } \\
\text { reel describing a typical } \\
\text { American airlift over Berlin. }\end{array}$ \\
\hline News reportage & & $\begin{array}{l}\text { The Fall of the Berlin Wall } \\
\text { (Part 1) -East Germany opens } \\
\text { the gates (BBC news 9th } \\
\text { November 1989) }\end{array}$ & $\begin{array}{l}\text { A BBC television news } \\
\text { coverage reporting from } \\
\text { Berlin on the night the } \\
\text { borders to West Berlin were } \\
\text { opened. }\end{array}$ \\
\hline Documentary & & Hungary 1956 - Part 2 & $\begin{array}{l}\text { A non-fiction documentary } \\
\text { showing footage of what } \\
\text { was happening in the } \\
\text { streets of Budapest in } 1956 .\end{array}$ \\
\hline
\end{tabular}

\section{Broadcast Media Content in the History Classroom: Findings from a Case Study}

\subsection{Students" Preferences of Media Images}

In order to understand which features of broadcast media have a bearing on students' motivation and engagement, I asked students to highlight their preferred types of broadcast images in helping them learn about the past. First, it is worth highlighting a cautionary remark offered by two students: Simon ${ }^{18}$ said that different types of moving images are "all important in their own way" and Jean remarked that "they all link together. I don't think you can arrive at a conclusion by watching one thing. You have to look at more things." Students' primary preference lay with documentaries (Table 1). Kyle explained his choice thus: "because there would be the narrator, the images and the footage." According to Kelvin, "a documentary is better than a newsreel because a documentary is released after an 
event happened and so it would be edited." In both interviews, Gavin and Kelvin said they still remembered the documentaries about the Hungarian revolt and the Cuban missile crisis respectively. In Paul's view, with a documentary "you get the explanation at the same time."

Five students said they preferred watching interviews or eye-witness accounts. Although in class these were not presented on their own but featured in documentaries, students nevertheless used these terms. Simon's explanation captured this general view: "Because they [people] would have lived during those times. It's not like you have an American author writing about the Poles and not knowing what happened. An eyewitness would know more on what is happening." While speeches were mentioned by four students, all of who were able to recall politicians' speeches watched during the lessons, nobody indicated a specific preference towards speeches in order to get to know what happened about an event. Even so, Noel noted that "you keep remembering speeches because they have those few phrases, for example ... 'Iron curtain' and 'Ich bin ein Berliner', and you remember them easily." Only Adrian and Charlo offered a negative opinion about documentaries: "A documentary would get boring because [the commentary] is ongoing" and therefore would give a lot of extra information.

\subsection{Developing Disciplinary Understandings}

Knowing about students' preferred media content is important because it is on that content that disciplinary knowledge has to be built. This is an important aspect of history education which, alongside substantive (content) knowledge, contributes to students' understanding of the past. ${ }^{19}$ Procedural knowledge is concerned with how substantive knowledge comes about and involves the use of disciplinary concepts such as evidence, interpretation and empathy. Essentially, this kind of knowledge requires analysing sources, such as understanding the context in which they were produced, their status and limitations. ${ }^{20}$ My primary interest in looking at procedural knowledge was to understand how moving images could contribute towards helping students understand history as a discipline. In particular, I was interested in understanding how broadcast media content were being used as sources of evidence.

Findings from this study showed that treating moving images as sources of evidence involved searching for clues, comparing and contrasting moving images, even with other sources, and using them to test historians' claims. It included considering the status, purpose and significance of the moving image. It also involved discussing the reliability as well as any problems which may arise when dealing with moving images. The most frequent component of evidence was searching for clues $(n=123)$ which involved me, as a teacher, asking probing questions such as, "What do these moving images show us about Malta during WW2?" verbally in class or, "What is there in the documentary to show you that Gorbachev was different from other Soviet leaders?" in a writing task. There were instances when it was necessary to compare and/or contrast the moving-image extract with other sources $(n=21)$, as shown in the following representative extract from the lesson 'Solidarność' in which I encouraged students to reflect on the sources used:

T Now, think about all the sources we've mentioned, read, discussed ... watched. Do these movingimages support what we've seen here-the photographs, what I've read out?

Franklin Yes.

T How do they support them?

Kelvin Because there you are reading and there you are seeing who said those words, who experienced those times.

T Ok. But is there consistency between the photographs, personal accounts, what we saw? How is this consistency shown?

Kyle When the video started, we saw people queuing outside a shop. And in the video we also saw people waiting outside. 


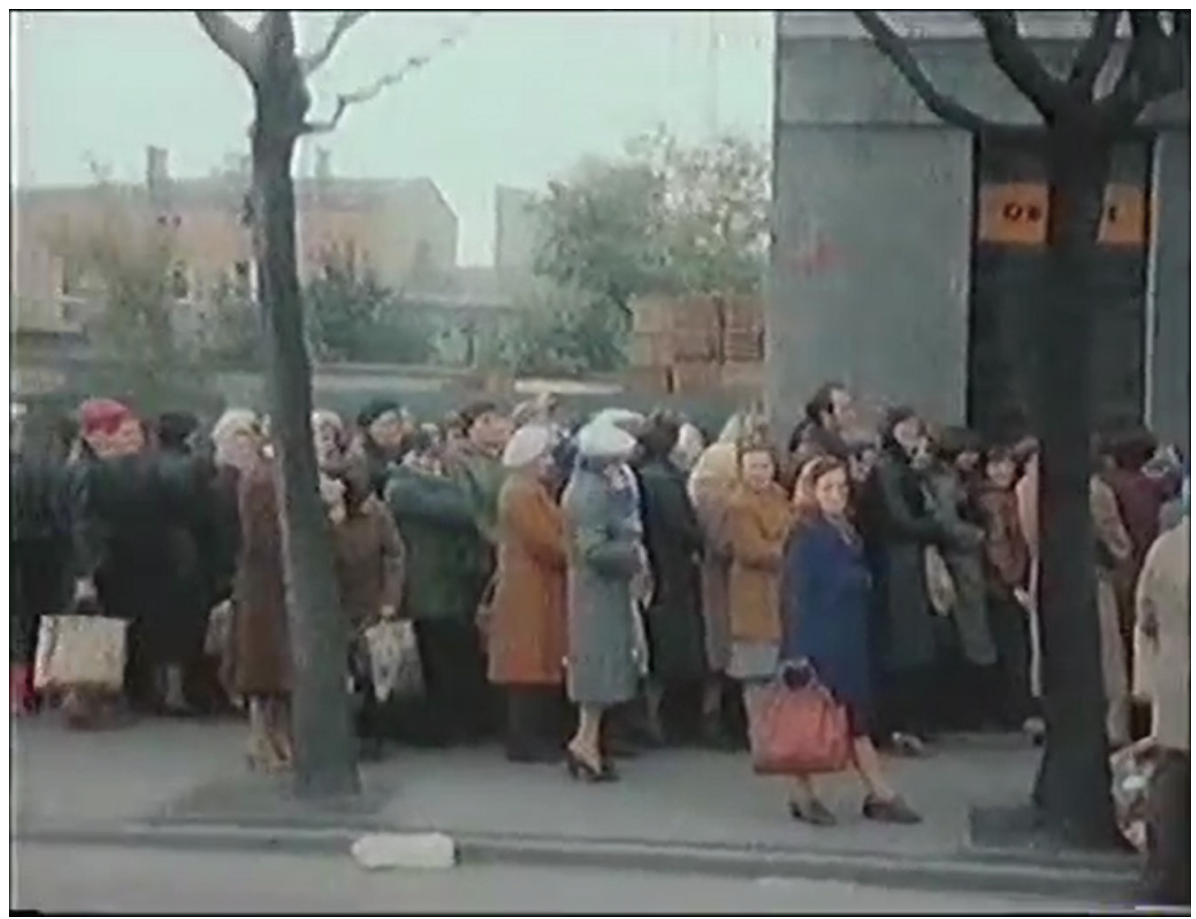

Video 1. Extracts shown in class: 00:00-06:00; 07:55-10:52.

An almost equal number of units of data were coded for status $(n=10)$, significance $(n=12)$ and reliability $(n=13)$. The status of the moving image was mentioned when in the lesson 'Solidarność' Daniel remarked, "So these [images] would be primary sources" and Noel asked, "Was the translation for the subtitles also done during that time?" Typically, the significance of the moving image was analysed with such questions from my part: "Why is the footage important for us today?" The reliability of moving images was mostly discussed with reference to the 'Cold War' topic. In the writing task related to the lesson 'Solidarność' students were required to think about this issue through the question, "Do you think these moving images are a reliable source to explain how the situation in Poland developed in the 1980s? Why do you think so?" Students' answers showed their awareness of how reliability depends on the way the contents of broadcast media are organised according to different points of view, as indicated in some responses:

Simon No, because they could be biased according to the side of the producer.

Clive $\quad$ Yes, because you get to see what was happening back then with your own eyes.

Paul Yes, they are reliable because they come from both [the] East and [the] West.

Franklin They are a reliable source because they show the actions taken, and together with the interviews to officials and civilians of the time, they show the suffering the Poles endured.

Most students were aware that there is no single version of events, that there is a potential bias in sources, and that there is the possibility of looking at different kinds of sources (primary, secondary, visual, written) which, through corroboration, can be used to construct a historical account. This is illustrated in the following interview extract, in response to my question about whether moving images helped them understand the context of an event:

Jon It depends on the company who produced them, for example British Pathé-they would be against the Germans.

Paul In order to understand you need to have more than one moving image.

Clive The one [moving image] you watch might show you a particular side, the British side for example, but then you would not see the German side. 
Using sources as evidence in the history classroom has for long been advocated among the history education community and has become mainstay pedagogy. ${ }^{21}$ The underlying argument for using sources as evidence was for students to 'think historically' 22 by putting sources under scrutiny so as not to be accepted as authoritative truth ${ }^{23}$. As students' exchanges in the above extracts demonstrate, with such knowledge gained from a history education in terms of using sources and thinking about reliability, possibly students would be more adept at making thoughtful judgements about contemporary issues as presented on the media, for example, in deciding what counts as true or fake news. The other second-order concepts were: causation, consequences, change and continuity, interpretation, significance and empathy. These were addressed in both whole-class discussions and writing tasks. Students adopted both the short-term and the long-term views of causes and consequences, ${ }^{24}$ and in discussing these students could see that there is no monocausal explanation for an event. ${ }^{25}$ With regards to change and continuity, students' questions showed they were more interested in the latter as opposed to change, which was mostly addressed through teacher questions. Whereas interpretation concerned mainly people particularly historical figures for instance, by looking at contrasting perspectives vis-à-vis Mikhail Gorbachev, significance was mainly dealt with in the context of events, for example by analysing the international import of the Cuban missile crisis. Students' answers to questions demanding empathic reasoning showed their attempts at adopting the perspective of people in the past ${ }^{26}$ while their interventions showing empathic feelings through comments as if they were there showed how they engaged with the actions of people and events shown in moving images.

\subsection{Interrogating Broadcast Media}

In view of Ormond's concern that "developing understanding of visual evidence is sometimes left to chance, perhaps backed by the argument that students live in a visual age and therefore have an innate ability to interpret visual culture successfully," ${ }^{7}$ interrogating broadcast media assumes great significance. Historical knowledge has a dual aspect: substantive knowledge, which refers to history's content knowledge; and procedural knowledge, which is concerned with how that knowledge comes about. Given this nature of historical knowledge, teacher questions have to address both strands in history lessons. ${ }^{28}$ Regarding substantive knowledge, teacher questions can address concepts (e.g., democracy, communism), particulars (e.g., the Berlin Wall, the Iron Curtain), people (e.g., John F. Kennedy, East Berliners) and the historical context (location, time) surrounding a particular event. Concerning disciplinary knowledge, teacher questions can target different second-order concepts like evidence (e.g., 'People started to trust him [Mikhail Gorbachev] rather less'. What is there in the documentary to prove this statement? Do you think this news coverage gives a reliable picture of what was happening?), causation (e.g., What led Churchill to say that an Iron Curtain has descended across Europe?); consequence (e.g., 'Soviet leaders were worried about free election'. What could a 'free election' mean?); change (e.g., What changes do you think take place following a terrorist attack?); empathy (e.g., How do you think life was like in a [war-time] shelter?) and significance (e.g., Why was it so important for the British to defend Malta?). Taking on the all-important expansive historical view ${ }^{29}$ involves challenging students with questions to get them thinking in terms of a big-picture understanding (e.g., How is this footage related to what was happening across Eastern Europe?). These questions are necessary for contextualising a historical event and to get students to think in terms of a wide-scale historical picture. Aimed at problematizing the knowledge arising from the broadcast media content, these questions contribute towards developing second-order concepts in relation to historical content. ${ }^{30}$

In my study, two factors were key to whole-class discussions: first, students' attention to detail; second, teacher intervention. Having to pay attention to a large amount of visual and aural data, students have to adopt a keen eye for observation. This call requires the teacher to target observation skills (e.g., What do we see happening? What are people seen to be doing?). As a teacher, my intervention took on various forms: introducing a broadcast image; asking questions; repeating phrases; and referring to students' verbal inputs to the classroom discussion. Typically, when introducing a moving image, I would describe briefly what the content is about and why it was going to be used. The underlying aim of repeating verbatim words and phrases was to emphasise an idea or ask something in relation to it. Going back to a student's utterance occurred when an image or a comment from the moving-image extract related to something already mentioned or when it was necessary to build the discussion on what students previously mentioned. 


\section{4 Limitations}

It was clear that the use of broadcast content in the history classroom may pose some logistical issues which, possibly, if not addressed would undermine important aspects of the learning process, namely, motivation, engagement and understanding. Depending on the visual quality and age of the moving-image source, it may be that some footage might not be clear enough. Regarding the aural aspect, as students' comments revealed, the commentator's diction may be too fast to fully grasp on a first listen. Further, the very nature of moving images requires watching and listening at the same time. This necessarily places certain demands on students' attention skills, as students cannot go back to a particular image, unless done by the teacher either purposefully or upon students' requests. Thus, certain visual details and auditory content might be overlooked.

There was some evidence coming from written data suggesting that students sometimes used broadcast images as sources of information, indicated by their narrative style in writing. While students in the present study did not appear to have encountered problems with using moving images as sources of evidence in whole-class dialogues by, for instance, avoiding discussing the interpretative nature of historical knowledge ${ }^{31}$ - mainly because the pedagogy adopted aimed at challenging them "to look not at a source but through it"32 - nevertheless in their extended writing tasks students did seem to bank on the historical details presented in the moving images without any disciplinary argumentation. This accords with research highlighting students' propensity to treat sources as uncontested information. ${ }^{33}$

\section{Implications}

\subsection{Choosing Educationally-relevant Broadcast Content}

Despite a rich audiovisual heritage,$^{34}$ searching among an array of online broadcast material in order to find the images that perfectly fit the syllabus, the lesson objectives and classroom requirements (e.g., students' abilities) may be daunting. An Internet search would result in a considerable amount of moving images, though not all would be suitable for classroom use. To avoid making online browsing a time-consuming exercise, it would be profitable to develop certain criteria, as I did in my study, to ensure the educational worthiness of broadcast content. Primarily, the broadcast moving image should be aligned with the syllabus requirements and hold potential for engaging students critically with episodes from the past. Second, the moving image should be age-appropriate and commensurate with students' abilities. Third, the clarity of the moving image should be such that the language used by way of the commentary, speeches or interviews is not equivocal, and the images are of good visual quality. Of course, broadcast moving images would vary in length and this would necessarily involve the teacher selecting the salient extracts to be shown, analysed and discussed in class.

Concerning online platforms, it is safe to say that YouTube, which was used in this study, offers an appropriate platform for making available archival material. It can be used in any classroom having good Internet connectivity and allows for content to be downloaded. Even so, keeping the educational angle in focus, how can YouTube channels be improved to help teachers find the relevant content? Considering other platforms (e.g., EUscreen and Historiana), how can the archival content earmarked for uploading be aligned with the school curricula? In the light of the teaching-learning context, what would the curatorial exercise on the part of museums and archives entail? Pertinent to any platform, ease of navigating the archival content is paramount. This means that for retrieval purposes, material has to be categorised ideally according to history syllabuses general themes. It would also be of benefit to users, whether students, teachers or researchers, if each clip is accompanied by a brief description of who the producer is, and when and on which television station and country it was aired in order to provide a useful context for analysis. Keeping history's disciplinary aspects in view, I suggest that juxtaposing European-wide broadcast content regarding specific historical events to 
allow for comparative pan-European perspectives would be advantageous to history education. Further, to avoid language barriers, having English subtitles would go a long way towards making content accessible in every possible way. Crucially, I suggest that any efforts in these regards should be guided by an understanding of what the purpose and scope of the archival material are, as well as a knowledge of what history curricula entail. In this way television history's outreach could be extended meaningfully to students attending various European educational institutions.

\subsection{Making Optimal Use of Broadcast Content}

Various non-optimal uses of feature film in the history classroom have been highlighted, such as using video without pausing for discussion, showing it as a reward or to manage behaviour. ${ }^{35}$ Building on this, and drawing on my study, I suggest that, primarily, a whole-class approach is adopted to analysing broadcast media. In this way, teacher-student dialogues will contribute to knowledge co-construction. Findings from this study have shown that moving images seemed to invite students to express themselves verbally every time they were used. An important finding concerned the importance of using broadcast content alongside other sources; as students remarked, moving images are insufficient on their own to understand a historical event. Thus, making optimal use of moving images as sources requires that moving images are not used as a stand-alone resource, perhaps as a filler or to replace the teacher, but always in the context of a historical event and alongside other sources (primary, secondary, written, pictorial, etc.) so that the importance of corroborating sources is encouraged.

It may help if discussion time is not outpaced by screen time. Extracts of moving images are of different durations. Because they have to be discussed in order to be analysed, it would be useful if such extracts are short (5-10 minutes). Having lengthy moving-image extracts may compromise students' attention and subsequently the entire educational value would be lost. Moreover, classroom discussion is greatly enhanced if moving images are paused to allow for questions to be asked and answered, to discuss the commentary, challenge students with any taken-forgranted opinions, and build on their prior knowledge.

With the sensory demands that are called into play when watching moving images, it will help to have an observational goal. The phenomenon of 'inattentional blindness' refers to our failure to notice unexpected yet perceptible stimuli in a visual scene while focusing on something else in the same scene. ${ }^{36}$ Therefore, through our habitual selective looking we let slide, unintentionally, important details from our visual field. Indeed, observation entails a complex process; Konnikova distinguishes between passive observation, which entails letting objects enter your visual field, and knowing what and how to observe and directing your attention accordingly. ${ }^{37}$ The importance of the latter type of observation was hinted at by Noel during an interview. Answering my question about how one would go about analysing moving images, Noel said that there is always something of interest in a moving image and added:

When there is, for example, a speech you would give importance to that person making the speech, and when there is the Berlin Wall you would give importance to the people. Not that you don't give importance to other things but you give importance to certain things.

Therefore, in an effort not to discard certain visual or auditory details it would be advantageous for teachers to encourage students to focus on the pertinent aspects of the moving image which have a bearing on the lesson's enquiry.

\subsection{Developing a Sense of Critical Visual Literacy}

I am in agreement with O'Connor's view of developing visual literacy in schools. ${ }^{38}$ Nowadays, in addition to mastering skills associated with the printed text, being literate has come to encompass the acquiring of skills required to master 
some degree of visual, media, digital and Internet literacy. ${ }^{39}$ Being visually literate implies being competent at analysing and evaluating images in order to interpret objects and actions as seen in pictures with the aim of creating meaning and communicating knowledge and understanding. ${ }^{40}$ This "encompasses the ability to be an informed critic of visual information, able to ethically judge accuracy, validity and worth." 41 In the context of a history classroom analysing broadcast media, a sense of critical visual literacy can be achieved by students being confronted with various issues: how a commentary can shape our reactions to, and perceptions of, a moving image; how news are reported; the provenance and purpose behind moving-images; the relationship between the producer and the audience; the propaganda implicit in the moving images; 42 elements of historical interpretation; alternatives that might have been considered; ${ }^{43}$ and the importance of multiperspectivity.

Key to achieving this is an awareness of the concept of evidence, the development of which is an important goal in history education. Extensive research has established that students' conceptual ideas about evidence progress from treating sources as information, to seeing sources as evidence from which inferences can be made, and to understanding that sources yield evidence when viewed in their historical context. ${ }^{44}$ Concerns have been raised due to research showing that students may fail to understand fully the interpretative nature of evidence. ${ }^{45}$ There are students who consider textbooks to be more reliable than primary sources. ${ }^{46}$ It may also be that students adopt an uncritical stance towards sources and thus treat them as given information. ${ }^{47}$ Clearly, the onus is on the teacher in moving students beyond simplistic views - a task which is not always easy ${ }^{48}$ - but which can be done with moving images in history lessons.

Having a curated content (e.g., British Pathé newsreels) means that aspects such as biases and propaganda are conspicuous. ${ }^{49}$ Therefore, rather than being dismissed as daunting, curated moving images should offer a platform for engaging students in meaningful historical enquiries. Indeed, it is the curated content that makes a moving image worth investigating because it will help sensitize students about the contested nature of historical knowledge, how narratives are constructed and how historians compete between various claims - all of which align with the syllabus objectives of placing evidence in context, detecting bias and identifying gaps and inconsistencies. ${ }^{50}$

Present findings suggest that second-order concepts were mainly driven by teacher questions which elicited students' responses about disciplinary aspects of history. From students' verbal and written data it was clear that such questions helped them see that there was more to what was being shown in moving images. In line with Counsell, according to whom a function of second-order concepts is to "turn content into problems," 51 the idea which I wanted to get across was that through questions the content presented in moving images could - and should be - problematized in ways similar to how historians commonly inquire into the past.

Indeed, in an age in which the Internet, film and television constitute sources of one's historical knowledge, ${ }^{52}$ and in which students passively consume audiovisual material, ${ }^{53}$ considering how the media create or influence our notions of the past in the history classroom assumes enormous importance. In the light of Levstik and Barton's remark that, "if schools are to prepare students for active citizenship in a democracy, they can neither ignore controversy nor teach students to passively accept someone else's historical interpretations," 54 the responsibility is on the history teacher to provide varied opportunities for students to nurture their evidential thinking. ${ }^{55}$

\section{Conclusion}

In an attempt to place more emphasis on harnessing the educational potential of moving images, this paper has sought to offer insights into how we can enliven broadcast media in the history classroom. In conclusion, it is to be remarked that as national and international events continue to be given extensive media coverage more than ever before, the availability of broadcast media content will keep increasing. It is possible that in the future, as syllabuses change to include recent historical events, the teaching and learning of history will have to depend more on the use of 
broadcast media as sources of evidence. Moreover, living in the information age, students are growing up in a society which puts great emphasis on visual information and will continue to come to school with their own particular knowledge of evaluating visual content. Indeed, the demands of the digital world and the use of technology in the classroom make it necessary to develop skills to navigate, and be competent at, analysing online content. Knowing how to critically analyse broadcast media content in the history classroom helps address this call. Finally, my hope is that this paper offers scope for researching further European television history from an education perspective, in particular to assess the content for educational purposes and gains in the classroom. This approach should make for a healthy balance between researching the content aspect of broadcast media and their educational potential for the teaching-learning classroom context.

\section{Notes}

1 Bryan Haworth, "Film in the Classroom," in The Historian and Film, ed. Paul Smith (Cambridge: Cambridge University Press, 1976), 157-168.

2 Terry Haydn, "Secondary History: Current Themes," in Debates in History Teaching, ed. lan Davies (London and New York: Routledge, 2017), 30-45.

3 Debra Donnelly, "Filmic Pedagogies in the Teaching of History: Research on and Recommendations for Using Video in the Classroom," International Journal of History, Learning, Teaching and Research 14, no. 1 (2016): 113-123.

4 Alexander Badenoch, Jasmijn van Gorp, Berber Hagedoorn, Judith Keilbach, Eggo Müller and Dana Mustata, "Old Stories and New Developments: Engaging with Audiovisual Heritage Online," VIEW Journal of European Television History and Culture 7 , no. 13 (2018): 1-5.

5 Alexander Cutajar, Motivation, Engagement and Understanding: A Study of Using Moving-image Sources in a Maltese Secondary History Classroom (Unpublished Ph.D. thesis, University of York, 2017).

6 Rudolf Stöber, "Historic Key Events and the Media," in The International Encyclopedia of Communication Vol. V., ed. Wolfgang Donsbach (Malden, MA: Blackwell Publishing Ltd., 2008).

7 Ben Walsh, Exciting ICT in History (Stafford: Network Educational Press Ltd, 2005).

8 Faye Sayer, Public History: A Practical Guide (London: Bloomsbury, 2015).

9 Directorate for Learning and Assessment Programmes [DLAP], "History option syllabus," Government of Malta, January 21, 2020, https://curriculum.gov.mt/en/Curriculum/Year-9-to-11/Documents/curric_f3_f5/syllabus_history_opt_f3_f4_ f5_2014.pdf

10 Ken Robinson and Lou Aronica, Creative Schools: The Grassroots Revolution That's Transforming Education (London: Penguin Books, 2016); Terry Haydn, "Introduction," in Using New Technologies to Enhance Teaching and Learning in History, ed. Terry Haydn (London and New York: Routledge, 2013), 1-5.

11 Sayer, Public History.

12 John E O'Connor, "History in Images/Images in History: Reflections on the Importance of Film and Television Study for an Understanding of the Past," The American Historical Review 93, no. 5 (1988): 1200-1209; Walsh, Exciting ICT in History; Paul B. Weinstein, "Movies as the Gateway to History: The History and Film Project," The History Teacher 35, no. 1 (2001): $27-48$.

13 Alan S. Marcus, Scott Alan Metzger, Richard J. Paxton and Jeremy D. Stoddard, Teaching History with film: Strategies for Secondary Social Studies. Second Edition (New York and London: Routledge, 2018); John E O'Connor, "History in Images/ Images in History".

14 Debra Donnelly, "Teaching History Using Feature Films: Practitioner Acuity and Cognitive Neuroscientific Validation," International Journal of Historical Learning, Teaching and Research 12, no. 2 (2013): 16-27.

15 Sonja de Leeuw, "Navigating Digital Archival Routes through European Television," Farewell Lecture, Utrecht University, May 16, 2018, https://dspace.library.uu.nl/handle/1874/375098

16 Ethical consent to carry out the research was obtained from the University of York and the Education Directorate within the Ministry for Education and Employment, Malta.

17 Micheline T. H. Chi, "Quantifying Qualitative Analyses of Verbal Data: A Practical Guide," The Journal of the Learning Sciences 6, no. 3 (1997): 271-315.

18 Student names were replaced with pseudonyms.

19 Haydn, Secondary History.

20 Alison Kitson, Chris Husbands, and Susan Steward, Teaching and Learning History 11-18: Understanding the Past (Berkshire: Open University Press, 2011). 
21 Terry Haydn, Alison Stephen, James Arthur, and Martin Hunt, Learning to Teach History in the Secondary School, fourth edition (London and New York: Routledge, 2015); Peter Lee, "Putting Principles into Practice," in National Research Council (U.S.). How Students Learn: History, Mathematics and Science in the Classroom. Committee on How People Learn, Targeted Report for Teachers, eds. John D Brandsford and M. Suzanne Donovan (Washington, D.C.: The National Academies Press, 2005); Christine Counsell, "Disciplinary Knowledge for All, the Secondary History Curriculum and History Teachers' Achievements," The Curriculum Journal 22, no. 2 (2011): 201-225.

22 Kitson et al., Teaching and Learning History 11-18.

23 Rosalyn Ashby, "Understanding Historical Evidence: Teaching and Learning Challenges," in Debates in History Teaching. Second edition, ed. Ian Davies (London and New York: Routledge, 2017); Ludmilla Jordanova, History in Practice (London: Arnold, 2000).

24 Christopher Chambers, "Teaching Causal Reasoning," in A Practical Guide to Teaching History in the Secondary School, ed. Martin Hunt (London and New York: Routledge, 2006).

25 Denis Shemilt, History 13-16 Evaluation Study (Edinburgh: Holmes McDougall, 1980).

26 Kitson et al., Teaching and Learning History 11-18.

27 Barbara Ormond, "Enabling Students to Read Historical Images: The Value of the Three-Level Guide for Historical Inquiry," The History Teacher 44, no. 2 (2011): 179.

28 For a discussion about a possible framework of questions for analyses see Alexander Cutajar, "Understanding the Past with Visual Images: Developing a Framework for Analysing Moving-image Sources in the History Classroom," The Educator 5 (2019): 113-115.

29 Lee, "Putting Principles into Practice."

30 Haydn et al., Learning to Teach History in the Secondary School.

31 Rosalyn Ashby, "Understanding Historical Evidence"; Bruce A. VanSledright, Assessing Historical Thinking and Understanding: Innovative Designs for new Standards (New York and London: Routledge, 2014); Keith Barton, "“I Just Kinda Know": Elementary Students' Ideas about Historical Evidence," Theory \& Research in Social Education 25, no. 4 (1997): $407-430$.

32 Ashby, "Understanding Historical Evidence," 140.

33 Ibid.

34 Badenoch et al., "Old Stories and New Developments."

35 Renee Hobbs, "Non-optimal Uses of Video in the Classroom," Learning, Media and Technology 31, no. 1 (2006): $35-50$.

36 APA Dictionary of Psychology, January 21, 2020, https://dictionary.apa.org/inattentional-blindness

37 Maria Konnikova, Mastermind: How to Think Like Sherlock Holmes (New York: Penguin Books, 2013).

38 O'Connor, "History in Images/Images in History."

39 Debra Donnelly, "Using Present-day Multi-modal Historical Representations in the Teaching of Conceptual Understanding in History," paper presented at the History Teachers' Association (Malta) / Faculty of Education, University of Malta The Michael A. Sant Memorial Lecture, Malta, October 11, 2017.

40 Suzanne Stokes, "Visual Literacy in Teaching and Learning: A Literature Perspective," Electronic Journal for the Integration of Technology in Education 1, no. 1 (2001): 10-19.

41 Susan E Metros, "The Educator's Role in Preparing Visually Literate Learners," Theory into Practice 47, no. 2 (2008): 103.

42 Walsh, Exciting ICT in History.

43 O'Connor, "History in Images/Images in History."

44 Peter Lee and Denis Shemilt, "A Scaffold, not a Cage: Progression and Progression Models in History," Teaching History 113 (2003): 13-23; Peter Lee, Rosalyn Ashby, Aldrich Dickinson, "Progression in Children's Ideas about History," in Progression in Learning, ed. Martin Hughes (Philadelphia, PA: Multilingual Matters, 1996); Denis Shemilt, "Adolescent Ideas about Evidence and Methodology in History," in The History Curriculum for Teachers, ed. Christopher Portal (London: The Falmer Press, 1987).

45 Bruce VanSledright and Jere Brophy, "Storytelling, Imagination and Fanciful Elaboration on Children's Historical Reconstructions," American Educational Research Journal 29, no. 4 (1992): 837-859.

46 Sam Wineburg, "On the Reading of Historical Texts: Notes on the Breach between School and Academy," American Educational Research Journal 28, no. 3 (1991): 495-519.

47 Ashby, "Understanding Historical Evidence."

48 Kitson et al., Teaching and Learning History 11-18.

49 Eggo Müller, "“Great stuff”: British Pathé's YouTube Channel and Curational Strategies for Audiovisual Heritage in a Commercial Ecosystem," VIEW: Journal of European Television, History \& Culture 7, no. 13 (2018): 1-12.

50 DLAP, "History option syllabus."

51 Christine Counsell, "Disciplinary Knowledge for All, the Secondary History Curriculum and History Teachers' Achievements," 217.

52 Walsh, Exciting ICT in History; Weinstein, "Movies as the Gateway to History."

53 Alan S. Marcus, “"It Is as It Was": Feature Film in the History Classroom,” The Social Studies 96, no. 2 (2005): 61-67.

54 Linda Levstik and Keith Barton, Doing History: Investigating with Children in Elementary and Middle Schools, 2nd edition (New Jersey: Lawrence Erlbaum Associates Publishers, 2001), 8.

55 Counsell, "Disciplinary Knowledge for All." 


\section{B i o graphy}

Dr Alexander Cutajar is a visiting lecturer at the Faculty of Education, University of Malta and Education Officer within the Quality Assurance Department (Ministry for Education, Malta). He has performed teaching duties in primary and secondary schools and has served as Head of Department of History. His PhD research, carried out at the University of York, explored issues of motivation, engagement and historical understanding in the history classroom. He has authored a history book (Remembering Sette Giugno 1919), chapters in history textbooks and papers about various aspects of history education. He is Public Relations Officer of the History Teachers' Association (Malta) and a trainer for EUROCLIO - European Association of History Educators. He has participated in various international conferences and workshops about history education. 